\title{
Preparing for the MFAEM Examination
}

\author{
PA Hunt, SR Lord, SC Taylor
}

\section{Introduction}

To qualify for higher professional training in Accident \& Emergency Medicine it is necessary to obtain a membership examination in any one of Accident \& Emergency Medicine, Surgery, Medicine or Anaesthetics (1). Until 2003 the options were included the MRCS, MRCP(UK), FRCA or a specific A\&E membership, the MRCSEd(A\&E), offered by the Royal College of Surgeons of Edinburgh. A part one examination from one of the other three disciplines is required along with the relevant clinical experience obtained during an appropriate junior training rotation in order to sit the MRCSEd(A\&E).

Since 2003, the Faculty of Accident and Emergency Medicine (FAEM) has offered a new membership examination, the MFAEM, for A\&E trainees which consists of two parts - A and B. To date there have been three sittings. It is well placed to become the established membership qualification for $\mathrm{A} \& \mathrm{E}$ higher professional training and is the logical first step on the road leading ultimately to the FFAEM, the speciality's current "exit exam", towards the end of higher professional training.

\section{Examination administration}

Enquiries and applications relating to both part $\mathrm{A}$ and part $\mathrm{B}$ examination diets are best directed to the Faculty of Accident \& Emergency Medicine (FAEM), based at 3543 Lincolns Inn Fields, London, WC2A 3PE, Tel: 020-7405-7071 (Fax: 020-74050318). Information is also available from their very informative website which gives up-to-date examination information, regulations and advice as well as downloadable versions of the examination application forms at: http://www.faem.org. uk/site/exams/mfaem/mfaem.htm

Written application forms with supporting paperwork (an up-to-date Curriculum Vitae and two passport photographs are required) and the relevant cheque must arrive in the Faculty office by the published closing date. In the case of part B, written confirmation of satisfactory completion of an exempting primary (from a parent college) is also required if the part $A$ MFAEM is not held.

\section{Eligibility}

The minimum entry requirements for part A are that the applicant is fully registered with the GMC and has at least 6 months experience of practice in a UK emergency department recognised for training (or equivalent). Guidance on the criteria for educational recognition of $\mathrm{A} \& \mathrm{E}$ posts can be found at the FAEM website.

The minimum entry requirements for part $\mathrm{B}$ are that the applicant has been successful in part A MFAEM (or the equivalent primary from another UK faculty college), is fully registered with the GMC and has 12 months experience of the practice of emergency medicine (in emergency departments recognised for SHO training or equivalent), together with two 6-month posts in hospital specialties related to emergency medicine, for example acute general medicine, paediatrics, trauma and orthopaedic surgery or anaesthetics. In contrast, the MRCSEd(A\&E) requires a minimum of a year of $A \& E$ and 6 month post registration in both medicine and surgery.

Examination timings and venues

The MFAEM examinations are currently held twice yearly and this year are based at the John Radcliffe Hospital in Oxford. The next diet for part $A$ is 15th September (closing date 28th July) and part B on 29/30th November and 1st December (closing date 27th August). The part B may take place over one or two days as candidates are split into groups for each component. There are limited numbers of spaces available and these are allocated on a first come, first served basis. It is essential to apply as early as possible as places are taken so quickly that applications may be deferred to the next sitting. Examination fees are currently $£ 200$ for part $A$ and $£ 375$ for part B.

\section{Format of Part A}

Part A consists of a single multiple choice question paper with no negative marking. There are 50 questions in total each consisting of 4 stems. The examination is designed to assess basic sciences as applied to the practice of Emergency Medicine. The basic sciences assessed include anatomy, physiology, pharmacology, pathology, microbiology, haematology and clinical biochemistry. Applied anatomy and physiology are core areas of knowledge for TS4 3BW 
Emergency Medicine with the anatomy of the upper and lower limbs and cardiorespiratory physiology being particularly important areas. This is reflected in the number of questions on these subjects. basic sciences underpinning the many nationally accepted guidelines available to UK emergency clinicians.

Other areas, including epidemiology, clinical examination and investigations, principles of evidence-based practice and basic statistics may also be assessed and indeed, at least 5 questions of the total 50 reflected these topics at the last sitting (February 2004). Some examples of previous part A questions are shown in Table 1. Previous experience has shown the pass mark to vary between $60-70 \%(69 \%$ in February 2004).

Table 1. Examples of part A MCQs.
1. In respiratory alkalosis:

a) cerebral arterioles constrict

b) the oxygen dissociation curve is shifted to the right

c) the concentration of ionised calcium increases

d) there is an increased risk of fits

2. The following are true of local anaesthetic nerve blocks:

a) Femoral nerve block may cause paraesthesia over the medial aspect of the calf and the medial malleolus

b) Infiltration of local anaesthetic $1 \mathrm{~cm}$ to the ulnar side of the palmaris longus tendon at the wrist will reliably produce a median nerve block

c) Infraorbital nerve block commonly results in adequate anaesthesia for suturing of upper lip lacerations

d) Anaesthesia of the pinna can be obtained by blockade of the great auricular nerve immediately anterior to the tragus

3. Acute dystonic reactions may occur following oral administration of:

a) Prochlorperazine

b) Diazepam

c) Metoclopramide

d) Haloperidol

4. The following substances increase insulin resistance:

a) Cortisol

b) Prolactin

c) Growth hormone

d) Endogenous adrenaline
5. The following infections are shown to be a transfer risk from needlestick injuries:

a) Hepatitis E

b) Plasmodium falciparum

c) Syphilis

d) Leptospirosis Overall, most of the questions are clinically focused with a particular emphasis on the

photographs, ECGs or radiographs as well as blood gas, haematology or biochemistry results. The intention is to test interpretive knowledge and clinical management decision-making skills.

\section{Examples of part B questions (data interpretation paper)}

1. This 3-year-old boy presented to the emergency department having been found screaming by his mother. He had been well 30 minutes before. $\mathrm{He}$ complains of pain in his leg and will not weight bear. His radiograph is shown below:

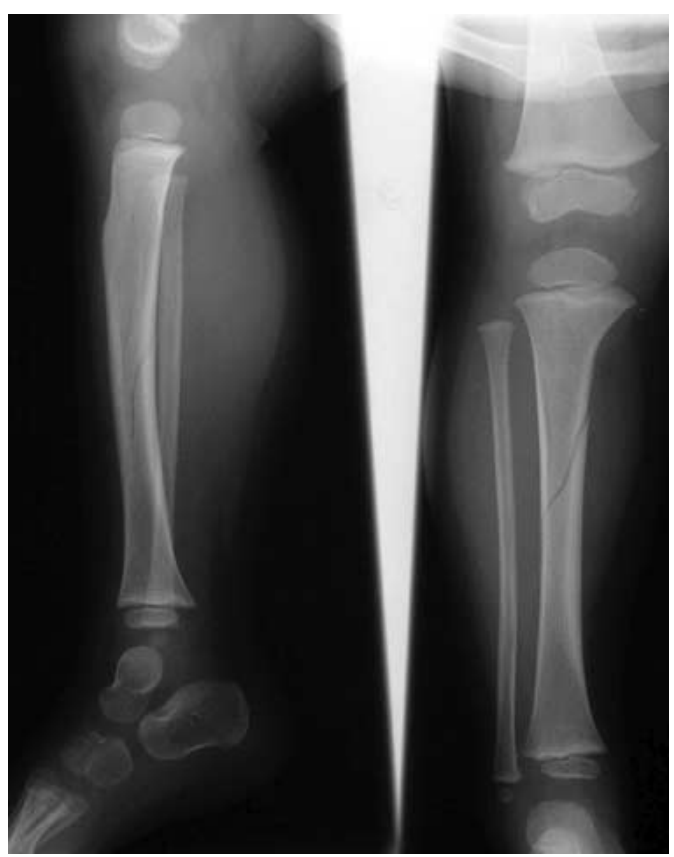

Figure 1.

a. What is the diagnosis?

b. How would you manage this child?

c. What must you consider as a cause of injury and how would you evaluate this?

2. This 65-year-old patient has been prescribed NSAIDs by her GP for a painfully swollen knee. She is also on medication for hypertension.

\section{$\mathrm{Na}+137 \mathrm{mmol} / \mathrm{l}$ $\mathrm{K}+7.6 \mathrm{mmol} / \mathrm{l}$ Crea $115 \mathrm{mmol} / \mathrm{l}$ Urea $9.9 \mathrm{mmol} / \mathrm{l}$}

\section{Format of Part B}

There are two components: a data interpretation question paper and an Objective Structured Clinical Examination (OSCE). Both parts must be passed individually in order to pass the whole exam.

The data interpretation question paper This section contains 15 3-part questions based around clinical scenarios using

Figure 2.

a. What is the electrolyte abnormality? What features may possibly be seen on the ECG?

b. What has caused this abnormality?

What type of antihypertensive medication may this patient be on?

c. Describe the emergency treatment for 
this condition.

3. This young girl is unresponsive and has a raised temperature of $39.7^{\circ} \mathrm{C}$. She has been suffering from a cough and sore throat for the last week.

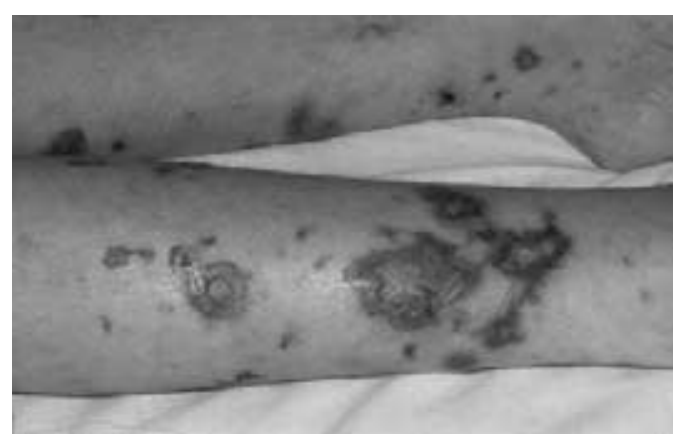

Figure 3.

a. What is your working diagnosis?

b. Which pre-hospital intervention could have improved her outcome?

c. How would you manage her condition acutely?

4. This young male has been caught between two lorry trailers. He has got difficulty in breathing with abnormal chest wall movement. The picture shows a supine radiograph of his thorax.

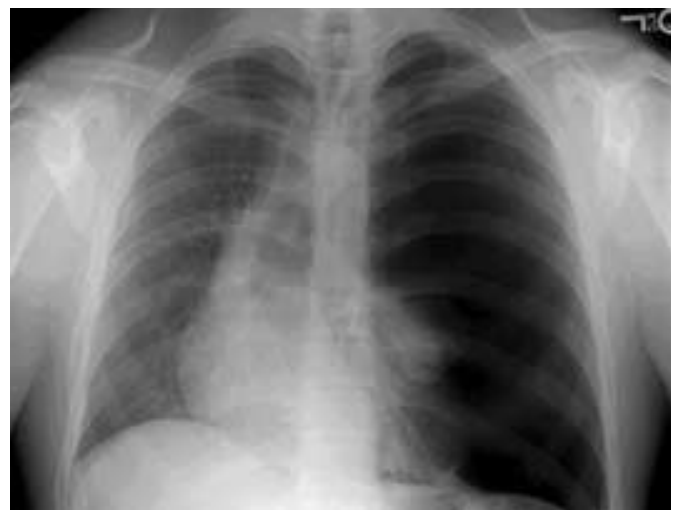

Figure 4.

a. What are the abnormalities on this radiograph?

b. How would you deal with these?

What do you need to do before?

c. Which complications would increase the mortality?

5. A 70-year-old gentleman has been brought in by the ambulance crew. He has had central chest pain for three hours, not relieved by GTN.

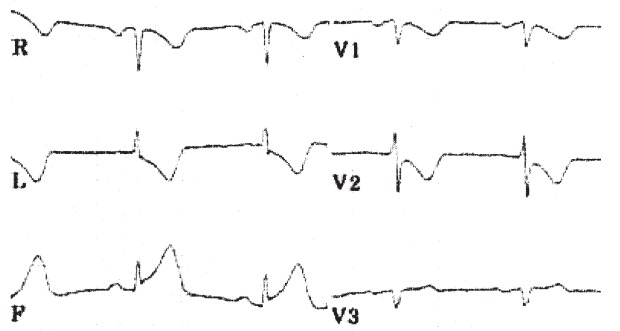

Figure 5. a. Describe the ECG rhythm.

b. How would you treat this patient? Name the absolute and relative contraindications?

c. What alternative treatment would you consider?

\section{The Objective Structured Clinical Examination (OSCE)}

The OSCE is intended as a comprehensive assessment of the knowledge, skills and attitudes required by a safe effective practitioner of Emergency Medicine. Most junior doctors (and a significant number of higher professional trainees!) will be aware of, or have experience of, OSCE-type clinical examinations.

This stage of the examination consists of 20 stations of which 2 are rest stations. During one of these rest stations the candidate is given written material to study for the next station. The candidate is assessed on the remaining 18 stations, each lasting 7 minutes and focused around a common $\mathrm{A} \& \mathrm{E}$ scenario, for example paediatric resuscitation, catheter insertion, breaking bad news and so on. A lot of the stations use actors to play the part, though there are some real patients with clinical signs (for example a murmur) to examine. Mannequins are also used for some of the scenarios.

The marking is against a pre-determined set of competencies. Additional marks may also be awarded by the patient/actor or examiner regarding their overall impression of the candidate's performance. Candidates receive a pass or fail mark for each OSCE station and must pass 14 out of 18 OSCE stations in order to be successful overall. Post-examination feedback is provided to unsuccessful candidates on request in a way which will be educationally helpful, not least of all for subsequent attempts.

\section{Marking systems}

The MFAEM assessment is competencybased with no pre-determined pass/fail rate. Those who show themselves to be competent against the agreed criteria will pass the examination. As the content of each component changes with each diet, so will the actual pass-mark depending on the degree of difficulty of each diet. The pass mark for the written paper generally varies between $50-60 \%$.

\section{Examples of OSCE stations}

1. This 17-year-old female patient has sustained a fall onto her outstretched left hand. She complains of tenderness and a reduced range of motion in the wrist. Xrays confirm a minimally displaced fracture of the distal radius and ulna. The radiographs are available. Apply a forearm plaster splint and give the relevant plaster advice.

2. A 45-year-old female patient was brought 
Table 2. Summary of knowledge and core skills.

\begin{tabular}{|c|c|}
\hline System / Area & Examples of specific subjects (or necessary qualifications) \\
\hline & KNOWLEDGE \\
\hline Cardiovascular diseases & $\begin{array}{l}\text { Chest pain assessment and treatment (thrombolysis), heart failure and pulmonary oedema, arrhythmias, } \\
\text { aneurysm. ALS qualification }\end{array}$ \\
\hline Trauma and orthopaedics & $\begin{array}{l}\text { General approach and specific MSK examination and management. Fracture treatment, acute and chronic } \\
\text { arthritis. ATLS qualification }\end{array}$ \\
\hline Anaesthesia & $\begin{array}{l}\text { Basic and advanced airway management. General, regional, local procedures. Sedation. Interaction with } \\
\text { intensive care department }\end{array}$ \\
\hline Shock & Differential diagnoses, fluid resuscitation, blood products and storage \\
\hline Pulmonary emergencies & Asthma, COAD, foreign body, pneumothorax, chest infection \\
\hline Gastrointestinal conditions & Acute GI bleed, abdominal pain evaluation, vomiting and dehydration \\
\hline Ophthalmology & Acute red eye, trauma, orbital cellulite, causes of visual impairment \\
\hline Metabolic emergencies & $\begin{array}{l}\text { Diabetic and other endocrine emergencies such as adrenal crises, electrolyte abnormalities, acid-base } \\
\text { disturbances }\end{array}$ \\
\hline Gynaecology and obstetrics & Ectopic pregnancy, PID, miscarriage, eclampsia \\
\hline Genito-urinary medicine & STDs, sexual assault, UTIs, testicular torsion, haematuria \\
\hline Infectious diseases & Hepatitis, HIV, TB, Malaria, PUO, Needlestick injury, childhood illnesses for example measles, mumps \\
\hline Toxicological emergencies & $\begin{array}{l}\text { Initial treatment of poisioning, agent-specific therapy, decontamination procedures, possible aspects of } \\
\text { terrorist action }\end{array}$ \\
\hline Childhood emergencies & $\begin{array}{l}\text { i.e. meningitis/ septicaemia, NAI, developmental paediatrics, croup/epiglottitis, asthma, fever, analgesia. } \\
\text { APLS qualification }\end{array}$ \\
\hline Environmental emergencies & Burns, hypothermia, drowning, electrical injuries, bites, anaphylaxis, heat illness \\
\hline ENT emergencies & Upper airway obstruction, epistaxis, foreign bodies, infections \\
\hline Neurological emergencies & Coma, headache, seizures, CVA, meningitis, unexplained collapse \\
\hline Behavioural emergencies & $\begin{array}{l}\text { Mental state examination, psychiatric manifestations of organic illness, DSH, suicide, psychosis, } \\
\text { drug/alcohol misuse }\end{array}$ \\
\hline Geriatric emergencies & Multi-system pathology and polypharmacy, collapse / syncope \\
\hline Maxillo-facial & Dental emergencies and max-fax fractures/ dislocations \\
\hline Social emergencies & Homelessness, overall patient care, frequent attenders, Munchausens, spouse / domestic abuse \\
\hline Dermatological & Common rashes, atopy, emergency causes of acute rash \\
\hline Haematological & Haemophilia, Haemoglobinopathies, blood dyscrasias \\
\hline Legislative & $\begin{array}{l}\text { Consent, competence, confidentiality. The Mental Health Act, The Children act, role of coroner, } \\
\text { organ/tissue donation }\end{array}$ \\
\hline & CLINICAL SKILLS \\
\hline Resuscitation & BLS, ALS, CPR. Defibrillator technique. \\
\hline Major trauma & Overall management (ATLS). Airway, breathing, circulation. \\
\hline Wound management & $\begin{array}{l}\text { Types of wound, preparation, anaesthesia, closure, foreign bodies, exploration and repair, joint aspiration/ } \\
\text { injection }\end{array}$ \\
\hline Splinting / immobilisation & Spinal immobilisation, log-rolling, limb immobilisation, plaster technique \\
\hline Reduction / manipulation & Techniques, anaesthesia - e.g. Biers/ Haematoma blocks \\
\hline ENT & Nasal packing and removal of foreign bodies \\
\hline Maxillo-facial & Dental anaesthesia, dental socket suture, plastic surgery techniques \\
\hline Ophthalmology treatments & Use of the slit lamp i.e. removal of foreign bodies. \\
\hline Imaging & Radiology, ultrasound, CT, MRI. Indications and cautions \\
\hline Laboratory results & Data interpretation including blood gases \\
\hline Transportation of patients & Handover, intensive care, referral \\
\hline & OTHER SKILLS / KNOWLEDGE AREAS \\
\hline Communication skills & Breaking bad or unexpected news, consultation skills \\
\hline Information technology & Health informatics, computer skills, software awareness \\
\hline Clinical governance & Including the audit cycle \\
\hline Medico-legal statements & Principles and guidelines such as professional vs. expert witness \\
\hline External liaison & Police, ambulance controllers, paramedics, coroner \\
\hline Dealing with complaints & Patients, relatives, personal, inter-colleague, outside specialities \\
\hline Major incident planning & MIMMS qualification, prehospital care considerations \\
\hline Literature surveys & Use of Medline, OVID, Cochrane database etc \\
\hline Statistics and research & Data evaluation, p-values, clinical applications, study designs \\
\hline Up to date publications & Relevant case reports, review articles, studies \\
\hline Professional attributes & Leadership, reliability, teamwork, self motivation \\
\hline
\end{tabular}


at the front doors of your $A \& E$ department by one of his mates. There is a vague history of a drug overdose or possibly long term substance abuse. The staff nurse has asked you to assess this gentleman's airway.

\section{Basic core subjects \\ General approach}

In terms of the general approach, successful candidates for the MFAEM should have a good understanding of, and appropriate experience in, the following areas:

1. The primary principles of patient-centred emergency care including resuscitation, the recognition of threats to life or limb, an understanding of "timeliness", correct documentation, interfaces with primary/ community care, therapeutics and pain control, the maintenance of patients' dignity and privacy, and relevant ethical issues including confidentiality.

2. Knowledge of the arrangement of associated emergency medical services including pre-hospital care providers and the ambulance service, paramedic training and function and involvement in major incident procedures (MIMMS).

3. The epidemiology of accidents and emergencies.

4. Accident prevention and health promotion.

\section{Knowledge and skills core}

Currently, a basic syllabus for the MFAEM does not formally exist. However, it would be reasonable to base such a syllabus upon the curriculum set out by the FAEM regarding the areas of clinical experience as well as the necessary skills and attributes expected of higher professional trainees in $\mathrm{A} \& \mathrm{E}$. A summary of this is shown in Table 2. It should be noted that this summary is intended to serve as a basic guide to more selective learning and development of appropriate clinical experience rather than to be treated as an exhaustive and detailed account of the knowledge and skills required for the MFAEM examination.

\section{Booklist and reference texts}

The choice of textbooks and reference material one uses is very much up to personal taste and individual learning techniques. A few months should be allowed for study before each exam. It is useful to talk to colleagues, especially $A \& E$ SpR's (preferably those who actually have the MFAEM!) to find their opinion on useful books. There are many handbooks and self-assessment texts which are readily available from most bookshops and Internet stores. The larger reference texts, such as Emergency Medicine by Tintinalli et al., are much more comprehensive (and generally much more expensive!). However, most are unsuitable for general background reading and instead are best utilised for reference purposes or for 'dipping into' as and when needed.

The summary shown at Table 3 lists a selection (in alphabetical order) of the useful textbooks to choose from for revision and exam preparation for both part $\mathrm{A}$ and part $\mathrm{B}$ of the MFAEM. The texts relating to clinical examination and imaging listed here (and presented in italics) are mainly of use for the part B. The texts shown in bold are those most highly recommended, if not to be considered required reading. Most of these books should also be available in local medical libraries.

Table 3. Selection of useful textbooks.

\begin{tabular}{|c|c|c|}
\hline Book title & Author(s) / Publisher & Price \\
\hline ABC of Major Trauma & Skinner, et al. BMJ books, 1999 & $£ 19.95$ \\
\hline ABC of Resuscitation & Colquhoun, et al. BMJ books, 2003 & $£ 19.95$ \\
\hline Accident $\mathcal{E}$ Emergency Radiology $-A$ survival guide & Raby, et al. Bailliere Tindall, 2003 & $£ 24.99$ \\
\hline Advanced Life Support & Advanced Life Support Group & (course fee) \\
\hline Advanced Paediatric Life Support & Advanced Life Support Group & (course fee) \\
\hline Advanced Trauma Life Support & American College of Surgeons & (course fee) \\
\hline An aid to the MRCP short cases & Ryder, et al. Blackwell Science (UK), 1998 & $£ 28.50$ \\
\hline Anaesthesia and Analgesia in Emergency Medicine & Illingworth \& Simpson.Oxford University Press, 1998 & $£ 35$ \\
\hline Applied Basic Science for Basic Surgical Training ${ }^{\star \star}$ & Raftery. Churchill Livingstone, 2000 & $£ 52$ \\
\hline Case Studies in Emergency Medicine & Freed, et al. Lippincott, 1996 & $£ 55$ \\
\hline Clinical Anatomy & Ellis. Blackwell, 2002 & $£ 29.95$ \\
\hline Immunology - An Illustrated Outline & Male. Mosby, 2003 & $£ 14.99$ \\
\hline Key Topics in Accident \& Emergency Medicine & Evans \& Burke. BIOS publishers, 2000 & $£ 29.95$ \\
\hline Lecture Notes on Human Physiology & Bray. Blackwell Science (UK), 1999 & $£ 19.95$ \\
\hline Major Incident Medical Management and Support (MIMMS) & Advanced Life Support Group. BMJ books, 2002. & (course fee) \\
\hline Oxford Handbook of Accident \& Emergency Medicine ${ }^{\star}$ & Wyatt, et al. Oxford University Press, 1999. & $£ 24.95$ \\
\hline Pocketbook of Orthopaedics and Fractures & McRae. Churchill Livingstone, 1999 & $£ 17.99$ \\
\hline Practical Emergency Medicine & Greaves \& Johnson. Hodder Arnold, 2002 & $£ 39.99$ \\
\hline Practical Fracture Treatment & McRae \& Esser. Churchill Livingstone, 2002 & $£ 35$ \\
\hline Psychiatry at a Glance & Katona \& Robertson. Blackwell Science (UK), 2000 & $£ 14.95$ \\
\hline Self-assessment in Accident \& Emergency Medicine & Greaves, et al. Butterworth Heinemann, 1996 & $£ 19.99$ \\
\hline Symptoms and Signs of Surgical Disease & Browse. Hodder Arnold, 1997 & $£ 24.99$ \\
\hline The ECG Made Easy & Hampton. Churchill Livingstone, 2003 & $£ 10.99$ \\
\hline 150 ECG Problems & Hampton. Churchill Livingstone, 2003 & $£ 15.99$ \\
\hline Trauma Care Manual & Greaves, et al. Hodder Arnold, 2000 & $£ 34.99$ \\
\hline Trauma Rules & Hodgetts, et al. BMJ books, 1997 & $£ 14.95$ \\
\hline
\end{tabular}




\begin{tabular}{|l|l|l|}
\hline Book title & Author(s) / Publisher \\
\hline 500 MCQs for the MRCP Part 1 & Baliga. Saunders, 1997. \\
\hline MCQs in Applied Basic Medical Sciences & Mokbel. Petroc Press, 1997 \\
\hline MCQs in Applied Basic Science for Basic Surgical Training & Jacob \& Samuel. Churchill Livingstone, 2000 \\
\hline MCQs in Physiology & Bindman, et al. Hodder Arnold, 1997 & $£ 11.99$ \\
\hline MCQs in the Basic Sciences for the MRCP Part 1 & Elborn \& Evans. Hodder Arnold, 1997 \\
\hline Self-assessment MCQs for the AFRCSEd Surgery in General & Royal College of Surgeons of Edinburgh, 1998 \\
\hline The Complete MRCS Vol 1 (Core modules) & Huang \& Winslet. Churchill Livingstone, 2000 & $£ 16.99$ \\
\hline The Complete MRCS Vol 2 (System modules) & Huang \& Winslet. Churchill Livingstone, 2000 \\
\hline
\end{tabular}

\section{MCQ books}

Unfortunately, unlike the MRCS and MRCP, there are currently no texts published specifically for the MFAEM part A. Therefore, a practical alternative approach for self-assessment and revision is to use a mixture of MRCS and MRCP MCQs. Numerous books of good quality MCQs of this type exist already. Especially useful are those which include decent answer sections for revision purposes. There are also several relevant texts which provide applied physiology and anatomy questions. Examples of recommended MCQ books are listed in Table 4.

\section{MCQs from other sources}

With time, a growing number of MCQs are sure to appear on the Internet as well as being written by and circulated between $\mathrm{A} \& \mathrm{E}$ trainees themselves. The 'Emergency medicine' section of doctors.net is a very useful resource and often contains postings including examination tips and MCQs from past papers. As the MFAEM examination becomes more popular and widely supported websites will undoubtedly spring up to fulfil the need for a growing bank of questions in a similar fashion to those already available for the other membership examinations (for example the popular PasTest series). Such an example of a very recently produced website is www.mfaem.info which is well worth looking at for information and more examples of questions from past papers and clinical assessments.

\section{Courses}

ALS, ATLS and APLS provider courses are certainly advisable, and possibly also MIMMS, before the part B examination as these help provide an element of fluency and poise when it comes to the clinical examination - especially in the case of resuscitation scenarios.

There are currently no specific courses for the MFAEM examination. However, the Academic Department of Emergency Medicine at the James Cook University Hospital in Middlesbrough will be holding a revision course for the MFAEM part B in the near future. The Royal College of Surgeons of Edinburgh offers a two-week revision course each spring which, while aimed towards the MRCSEd(A\&E) exam- ination, is undoubtedly helpful for the MFAEM examination as well. Announcements about appropriate study and revision courses for A\&E training are regularly updated and can be found at: http://www. baeta.co.uk

\section{Exam technique \\ Part A}

Much like other MCQ papers for MRCS, MRCP and so on, the key to passing part A of MFAEM is to practice as many questions as possible. If planning to study in a small group then writing questions in the correct format using information from a book such as the Oxford Handbook to test colleagues may be a useful revision technique.

When the time comes to sit the examination it is important to answer ALL the questions - tick random boxes if running out of time! (Though this is quite unlikely as there is normally more than adequate time for the examination). As there is no negative marking some marks will inevitably be scored from sheer guesswork, albeit informed guessing preferably. If one has no idea at all for a question then it is worth ticking 'true' based on the fact that MCQ papers are thought to have proportionally more true answers than false ones (2). Also remember to read both the original question and the stem very carefully, preferably twice, before answering as though it may appear familiar it may be subtly different due to a small change in the wording.

Overall the MCQ paper is a fair assessment and adequate clinical experience in $A \& E$ practice with a sound, broad base of medicine, surgery and applied physiological knowledge should be more than sufficient to pass it.

\section{Part B - The data interpretation paper}

Study preparation for the written component of part $\mathrm{B}$ follows along the same lines as that for the MCQ paper. Again, a broad base of knowledge is required but the emphasis of the questions this time is to test the candidates' interpretation of results and their clinical management decision-making skills. Experienced candidates with a wide variety of jobs under their belt may find the examination less challenging than their more junior colleagues. 
When considering the clinical scenario it is vital to imagine one is treating the patient in reality. A safe, straightforward and common sense 'A\&E' approach is all that is required and the examiners are not trying to trick candidates. Questions should not be answered like an essay - simple bullet points with short explanations are fine. It is useful to keep in mind the mantra of 'ABC' and approach the management answers firstly from the point of view of basic immediate treatment and then to discuss the specific therapies. A detailed knowledge of all the fine minutiae is not required to pass the question.

It has been noted in previous diets that the wording of questions can sometimes be a little vague or ambiguous. Also, criticism has been levelled by candidates in the past regarding the quality of the reproduction of radiographs, photographs and ECG rhythms which can be distracting. However, by attempting to judge where the scenario may be heading, and remembering that common things are common, it should be possible not to end up straying too far off the point of the question.

An additional feature of the data interpretation paper is a written triage exercise testing the candidates' ability to triage and prioritise patients according to UK emergency department triage guidelines. As the written triage question is at the end, candidates need to make sure that they allow enough time for this as the marks count double. The maximum time allowed for completing the paper is 90 minutes, allowing roughly 6 minutes per question. The pass mark for the paper generally varies between $50-60 \%$ so if stuck on a question it is advisable to move on and then go back afterwards if there is time.

\section{Part B - The Clinical (OSCEs)}

The stations are divided roughly into:

1. Practical skill stations (for example airway, breathing, circulation, suturing, plastering, catheterising).

2. Clinical examining stations (for example the cardiovascular system).

3. Clinical scenario stations (for example acute MI, subarachnoid bleed, overdose,

Table 5. Rules for OSCE examinations.

1. NEVER ARGUE WITH THE PATIENT/ACTOR OR EXAMINER!

2. Introduce yourself to the patient/actor and examiner.

3. Be kind and polite to the patient.

4. Do not hurt the patient! (This is especially bad if they are acting and don't have a real injury!)

5. Take an appropriate history if required.

6. Try to pick up on any non-verbal cues.

7. Perform a thorough, 'by-the-book', accurate though focussed examination.

8. Talk your way through things and make your observations more pronounced a bit like your driving test.

9. Discuss any positive or negative signs noted relevant to the history.

10. Discuss the findings with the examiner.

11. Formulate your differential diagnosis clearly stating your primary diagnosis.

12. Discuss aspects of treatment as required. psychiatric assessment, etc).

4. Resuscitation scenario stations (ALS, APLS, ATLS, defibrillator safety).

5. Communication skills stations (for example such as breaking bad or unexpected news, referring a patient to an 'uncooperative' specialist, postexposure HIV / hepatitis prophylaxis counselling, post-coital prophylaxis counselling).

When it comes to the approach to, and examination of, the patient nothing is better than practice. It is important to ask a colleague, especially a senior one such as an $\mathrm{A} \& \mathrm{E} \mathrm{SpR}$, to go through the common scenarios and clinical examinations regularly and often before the examination. An element of 'slickness' at the OSCE stage will be noted by the examiners and the knowledge of a well-performed assessment can help bolster confidence and conquer any 'stage fright' from the first station. However, it is important to temper any selfassuredness with a degree of professional humility. Non-verbal communication and overall 'bedside' manner will be assessed carefully by the examiners and cockiness or arrogance is unlikely to be considered very favourably. If a station seemed to go badly the only approach is to try and forget it and move on.

Overall, the sort of material presented in the clinical examination is the same as you might be seen in everyday clinical experience in A\&E. Again, the examiners are not trying to catch people out.

The basic rules for candidates sitting OSCE examinations are shown in Table 5.

\section{Summary}

The MFAEM may take over as the primary membership examination for progression to higher professional training in Emergency Medicine. As a relatively young examination it still suffers from a lack of associated study material and a formal syllabus.

The emergence of a specific membership examination such as MFAEM represents the growth in stature of $A \& E$ as a speciality in its own right. As the examination becomes more popular and growing numbers of doctors apply there will be a similar expansion of study material and available resources. MRCSEd(A\&E) remains a solid alternative and eligibility for this examination is similar to MFAEM part B. However, success at a relevant part one is required before sitting this. The MFAEM part $A$ is more balanced and relevant primary examination for $\mathrm{A} \& \mathrm{E}$ trainees but if one is interested in dual accreditation or has a specific interest in another speciality then sitting the MRCP, MRCS or FRCA may be more appropriate before approaching the MFAEM part B or MRCSEd(A\&E). 


\section{Further information}

There is a large amount of further information and numerous resource sites available for anyone interested in the MFAEM examinations, as well as general information for $\mathrm{A} \& \mathrm{E}$ trainees, most of which is readily available on the Internet. Table 6 lists some of the various websites that may be of interest to potential candidates.

Table 6. Useful website addresses.

\begin{tabular}{|l|}
\hline http://www.faem.org.uk \\
\hline http://www.baem.org.uk \\
\hline http://www.baeta.co.uk \\
\hline http://www.trauma.org \\
\hline http://www.traumacare-uk.com \\
\hline http://www.resus.org.uk \\
\hline http://www.mfaem.info \\
\hline
\end{tabular}

\section{References}

1. Leigh-Smith SJ, Porter CJ, Greasley LA. 2003. Preparing for the MRCSEd (A\&E). I R Army Med Corps; 149: 330-334.

2. Holsgrove G, Elzubeir M. 1998. Imprecise terms in UK medical multiple-choice questions: what examiners think they mean. Medical Education; 32(4): 343-50. 